Article

\title{
Distributions of Particle Sizes in Black Soil and Their Environmental Significance in Northeast China
}

\author{
Binghe Yan ${ }^{1,+}$, Yulan Zhang ${ }^{1,+}$, Shuying Zang ${ }^{1,2}$, Qiang Chen ${ }^{1}$ and Li Sun ${ }^{1,2, *}$ \\ 1 Heilongjiang Province Key Laboratory of Geographical Environment Monitoring and Spatial Information \\ Service in Cold Regions, Harbin Normal University, Harbin 150025, China; ybh@hrbnu.edu.cn (B.Y.); \\ zyl@hrbnu.edu.cn (Y.Z.); zsy6311@hrbnu.edu.cn (S.Z.); chenqiang2016@hrbnu.edu.cn (Q.C.) \\ 2 Heilongjiang Province Cold Region Ecological Safety Collaborative and Innovation Center, \\ Harbin 150025, China \\ * Correspondence: sunli_wabb@163.com \\ + These authors contributed equally to this work.
}

Citation: Yan, B.; Zhang, Y.; Zang, S.; Chen, Q.; Sun, L. Distributions of Particle Sizes in Black Soil and Their Environmental Significance in Northeast China. Sustainability 2021, 13, 3706. https://doi.org/ $10.3390 /$ su13073706

Academic Editor: Nádia Luísa Castanheira

Received: 17 February 2021

Accepted: 24 March 2021

Published: 26 March 2021

Publisher's Note: MDPI stays neutral with regard to jurisdictional claims in published maps and institutional affiliations.

Copyright: (c) 2021 by the authors. Licensee MDPI, Basel, Switzerland. This article is an open access article distributed under the terms and conditions of the Creative Commons Attribution (CC BY) license (https:/ / creativecommons.org/licenses/by/ $4.0 /)$.

\begin{abstract}
In recent years, black soil has decreased and degenerated heavily due to complicated functions of natural and artificial factors. Hence, characterizing distributions of particle sizes in black soil and their environmental influencing factors is important for understanding black soil degradation. A total of 116 surface soil samples in the top $20 \mathrm{~cm}$ from a typical black soil region in northeastern China were collected, and the spatial distribution of particle size parameters were characterized. Particle size-sensitive components were extracted quantitatively using the log-normal distribution function, and their environmental implications were investigated. The contents of black soil mechanical composition ranged from $7.8 \%$ to $79.3 \%$ for clay, $17.7 \%$ to $80.3 \%$ for silt, and $0 \%$ to $73.7 \%$ for sand, respectively. Median particle size ranged from 1.71 to $142.67 \mu \mathrm{m}$, with a coefficient of variation of $60 \%$, indicating silt accounted for the majority of the composition. Four environmentally sensitive components were identified, including long-distance transported airborne deposits of clay dust (C1), successions from local parent materials (C2), short-distance deposits of silt particles (C3), and a component strongly disturbed by human activities (C4). C1 and C2 had relatively low variations, with $\mathrm{C} 1$ exhibiting the smallest variation, and $\mathrm{C} 2$ contributing highest proportion, showing no significant differences across all samples. C3 widely existed across samples, suggesting common wind erosion within the black soil region. C3 and C4 varied spatially, which was caused by the low vegetation coverage and high human disturbance of agricultural topsoil. The results suggest that windbreaks should be encouraged to reduce wind erosion in the black soil regions.
\end{abstract}

Keywords: particle size; frequency distribution curve; wind erosion; environmentally sensitive component; black soil

\section{Introduction}

Particle size is one of the most important physical characteristics of soils. Soil particle size is affected by multiple factors, such as soil parent material, climate, biological activities (faunal and floral communities), topography, and human activities [1]. The size of individual particles and the makeup of different sized particles in the soil are determined by the interactions between the source of soil particles and external environmental impacts [2]. Soil particle size makeup is therefore commonly used in detecting events in soil formation and studying mechanical dynamics in soil particle transportation [3,4]. Research has shown that changes in land use and land cover, environmental media and forces, and the styles and intensity of human activities can not only change the physical and chemical properties of soils [5], but also significantly impact their resistance to wind erosion, water capacity, and nutrient conditions, which in turn influence the direction and amplitude of changes in the soil environment [6-9]. 
The particle size frequency distribution curve, which can be derived from a particle size analyzer, is in large determined by the form and media of soil particle transportation. Given certain combinations of particle transportation form and media, the size of the transported particles follows a single-variable normal distribution [10]. Natural sediment particles usually display multi-component, multi-state distribution, shown as smooth and polymodal curves on the particle size frequency diagram [11,12]. Up to now, researchers have developed a few methods to extract particle size-sensitive components from particle size frequency distribution curves, including principal component analysis, end-member modeling, Weibull distribution function, the particle level standard deviation algorithm, and logarithmic normal distribution function [13-17]. Among these common methods, the first four particle size-sensitive components extracting methods were more suited to being applied in a homogeneous environmental medium without large spatial differences, such as lake core sediments, soil profiles, and ice cores. Conversely, the log-normal distribution fitting method is better suited for samples with large spatial heterogeneity by extracting qualitative and quantitative components from polymodal curves resulting from multiple overlapping soil forming and transporting forces. In recent years, particle size frequency distribution curves have been widely used as reliable evidence for determining the aeolian and aquatic forces that contribute to the formation of yellow soil, desert sand, lake, and river fine particle sediments [18]. However, there are relatively few studies that focus on the implications of soil particle size frequency distribution curves.

Wind erosion has adverse effects on soil productivity, land degradation, and agricultural sustainability [19]. Zhang and Dong [20] discovered that the loss of fine particles in surface soil in northwestern China caused by wind erosion is a major contributor to desertification in the region. Yan et al. [21] proposed that wind erosion is a major reason for the loss of soil organic matters in grass land areas typical in Inner Mongolia. It is not difficult to see that, so far, soil particle studies have mostly focused on areas heavily impacted by wind erosion, with emphases on characterizing signatures and magnitudes of the erosion, but the impact of wind erosion on the black soil region in northeast China has not drawn a lot of attention from researchers.

As one of the most important commercial crop production centers in China, the black soil region in northeast China is located in a semi-arid, semi-humid monsoon climate zone. Although the time of land reclamation in the black soil area is relatively short, the area of accelerated erosion after reclamation is very wide. The black soil layer has decreased from $70-100 \mathrm{~cm}$ in the early reclamation period to $16-70 \mathrm{~cm}$ in the $1980 \mathrm{~s}$, and the organic matter contents has decreased from $6-15 \%$ to $1.98 \%$. Soil erosion reduces the thickness of the effective soil layer, deteriorates the physical and chemical properties of soil, and leads to the decrease of land productivity. In recent years, due to environmental changes, especially the increasing wind erosion, and high-intensity agricultural activities, black soil quality has severely deteriorated as a result of loss of surface fine particles, organic matters, and nitrogen and phosphate nutrients. The particle size characteristics of black soil influence the permeability and water and nutrient capacity of the soil; thus, they are important parameters for the growth and yield of crops. Therefore, the present study focused on typical agricultural topsoil in the northeast China black soil region, and the specific aims were to (1) measure and compare the regional differences of mechanical composition and particle size parameters, (2) investigate the characteristics of the particle size frequency distribution curves and identify the particle size-sensitive components by log-normal distribution fitting method, (3) evaluate the environmental implications of the particle size-sensitive components, and finally, analyze the spatial distributions of contribution rates of particle size-sensitive components of black soils.

\section{Materials and Methods}

\subsection{Study Area}

The research was conducted in seven counties and cities located in the black soil region in northeast China: Baoquan County (BQ), Kedong County (KD), Keshan County (KS), 
Beian City (BA), Yian County (YA), Lindian County (LD), and Fuyu County (FY) (Figure 1). The geographic coordinates of the study area ranged from $46^{\circ} 49^{\prime} 12^{\prime \prime}$ to $48^{\circ} 32^{\prime} 24^{\prime \prime} \mathrm{N}$ and from $123^{\circ} 59^{\prime} 24^{\prime \prime}$ to $127^{\circ} 52^{\prime} 12^{\prime \prime} \mathrm{E}$ with a total area of $27,479.3 \mathrm{~km}^{2}$. The climate is classified as a temperate semi-humid continental monsoon climate, with four seasons in a year: rainy and hot summers, cold winters, and dry and windy springs and autumns. The annual average temperature is $1.2-2.6^{\circ} \mathrm{C}$. The annual mean total precipitation is $455-490 \mathrm{~mm}$, and the annual mean evaporation is $440-450 \mathrm{~mm}$. The annual average wind speed is $3.1 \mathrm{~m} / \mathrm{s}$. April and May are the windiest months of the year, with a month-average wind speed of $4.5 \mathrm{~m} / \mathrm{s}$ and a maximum wind speed of $22 \mathrm{~m} / \mathrm{s}$ in April. Annually, there is an average of 72 days with a wind level of or above level V (>8.0 m/s), making up $51 \%$ of all windy days each year. The topography of the region is undulating tableland, with wide valleys and hills and long and gentle slopes. The elevation lowers from the northeast to the southwest, ranging from 145 to $300 \mathrm{~m}$ above sea level (some un-sampled forested areas in Beian City have elevations of $460 \mathrm{~m}$ ). The soil in the region mainly consists of black soil and chernozem. Kedong, Keshang, and Baiquan Counties have typical black soil; Yian and Lindian Counties have a mixture of black soil and chernozem; and Beian City and Fuyu County have black soil and chernozem, along with some gleysols, luvisols, and organic soil. The most common land usage in the area is agriculture. Farmland area takes up over $69.6 \%$ of the total land area.

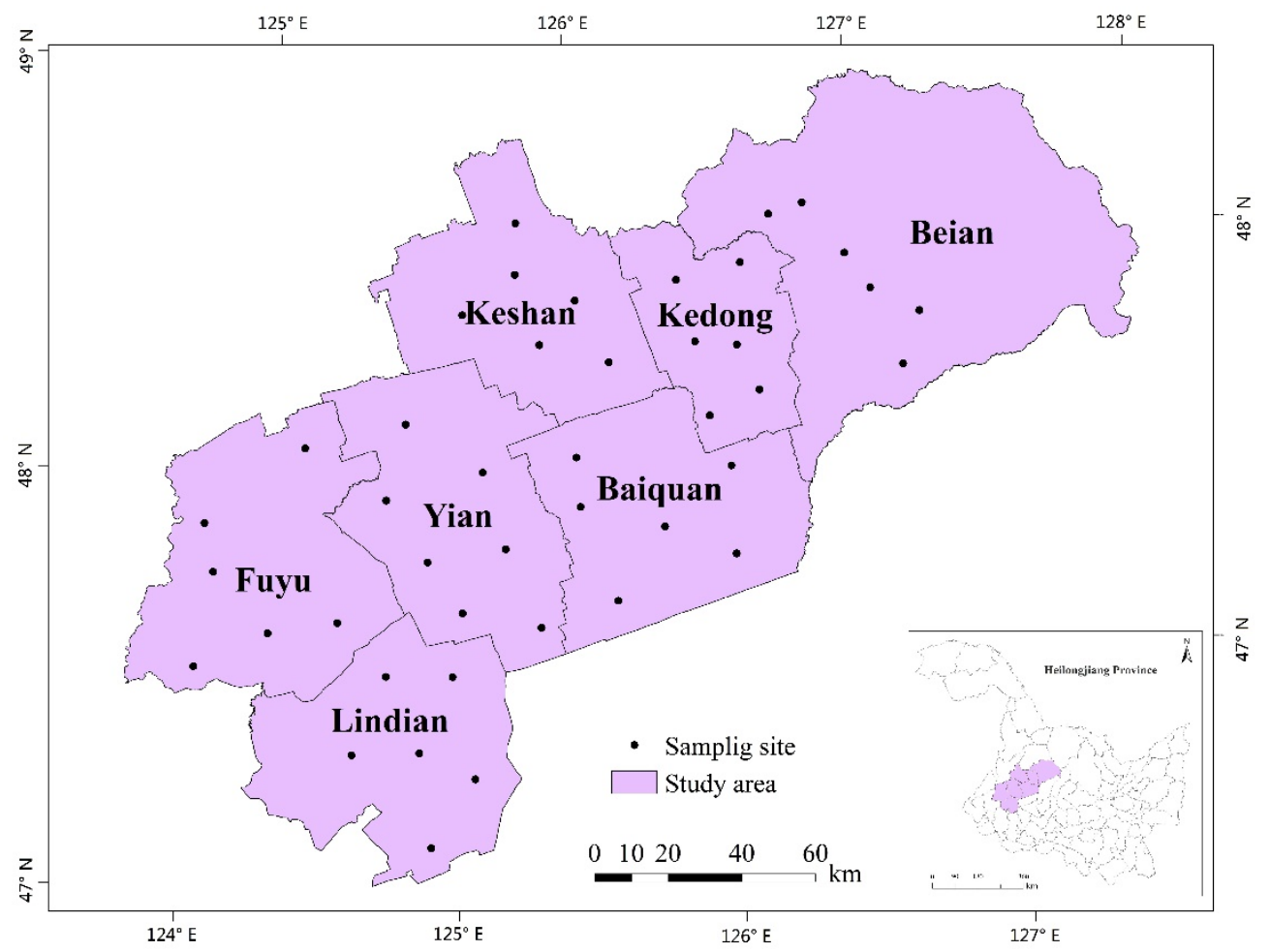

Figure 1. Studied areas and distribution of sampling sites.

\subsection{Sampling and Sample Analysis}

Most areas within the sampled region are of agricultural uses. Therefore, we took soil samples from farmlands for this experiment. In order to avoid variability introduced by plowing, we took soil samples in April 2015 before the growing season began. According to the even distribution sample principle, we determined 6 sampling locations per county/city, each separated by one $1 \mathrm{~m} \times 1 \mathrm{~m}$ unit, resulting a total of 42 sampling locations. Three soil samples were taken from each sampling location using the diagonal sample method [22]. Hence, 126 samples were collected from the top $20 \mathrm{~cm}$ of surface soil. The geographic coordinates of each sampling point were taken with a hand-held GPS device (Figure 1). The soil samples were dried at room temperature in the lab, and dried soil samples were 
sifted with a $2 \mathrm{~mm}$ sift to get rid of large residues before particle size composition was characterized.

One gram of the soil sample was prepared with $20 \mathrm{~mL}$ of $5 \%$ hydrogen peroxide, $20 \mathrm{~mL}$ of $5 \%$ hydrochloric acid, and $10 \mathrm{~mL}$ of $0.05 \mathrm{~mol} / \mathrm{L}$ sodium hexametaphosphate solution to remove organic matters and calcium carbonate and to minimize the effect of cementation on particle size characterization. The soil-particle size composition was measured with a Malvern laser particle-sizing instrument (Mastersizer 2000). The range of particle size detection was $0.02-2000 \mu \mathrm{m}$ in diameter. The measured particle size composition ("contribution rate" of each particle size class) was denoted with weight percentage of each particle size class. The measurement was replicated three times on each soil sample, and measurement errors were all within $\pm 3 \%$. Outlier samples were excluded from the analysis, resulting in only 116 soil sample measurements for data analysis and discussion. Using the soil-particle size classification guideline proposed by Wang et al. [23] and Ma et al. [24], we classified soil particles into clay $(<4 \mu \mathrm{m})$, silt $(4-63 \mu \mathrm{m})$, and sand $(>63 \mu \mathrm{m})$ and further classified silt particles into fine silt $(4-16 \mu \mathrm{m})$ and coarse silt $(16-63 \mu \mathrm{m})$. Other character parameters of the soil samples (medium particle diameter, Md; standard deviation, $\sigma_{I}$; skewness, $\mathrm{Sk}$; and kurtosis, $\mathrm{Kg}$ ) were calculated and diagramed using Folk and Wood's formulas [18].

\subsection{Sensitive Particle Size Component Extraction}

Sensitive components were mathematically defined and isolated from the particle size distribution curve using the log-normal distribution function. This method took the particle diameter of each sensitive component as an argument and calculated the percentage of each particle diameter using the Formula (1) and through fitting the sum of all function values across all sensitive components to minimize the residual between the fitted particle size distribution curve and the real particle size distribution curve of each sample. Other component parameters, such as mean particle diameter and standard deviation, could also be derived. For multi-component log-normal distribution function, the distribution curve followed the following formula:

$$
F(\operatorname{Lg} x)=\sum_{i=1}^{n} C_{i} \frac{1}{\delta_{i} \sqrt{2 \pi}} e^{-\frac{\left(\lg x-\lg \alpha_{i}\right)^{2}}{2 \delta_{i}^{2}}}
$$

In Formula (1), $\alpha_{i}$ and $\sigma_{i}$ stand for the mean and standard deviation, respectively, of the particle diameter of component $i$. $C_{i}$ is the percentage of component $i$ in reference to the whole sample $[18,25]$.

\subsection{Statistical and Spatial Analyses}

Statistical analysis was carried out using SPSS 22.0 software. Analysis of variance (ANOVA) was used to detect differences between locations on all particle size parameters. Least significant difference (LSD) statistics were used to establish significance $(p<0.05)$. Particle size-sensitive component spatial differential distribution was analyzed with the Kriging method under Geostatistical analysis in ArcGIS 10.2.

\section{Results}

\subsection{Soil Particle Size Characteristics}

All surface soil samples collected from black soil in northeast China had a maximum particle diameter smaller than $1000 \mu \mathrm{m}$, which was especially due to the case that black soil contains more nutrients than other soils. The overall mechanical composition across all samples is presented in Table 1 . The most abundant composition was silt, with the contents of fine silt and coarse silt ranging from $6.3 \%$ to $51.6 \%$ and $0.8 \%$ to $49.6 \%$, respectively. Clay accounted for $7.8-79.3 \%$, and sand was relatively low across the majority of locations except for in FY County, which accounted for 0-73.7\%. Clay content in black soil was significantly higher than that of Quaternary red earth [26], purplish soil in Chongqing [27], and loess in 
Loess Plateau [28]. This signature particle size characteristic sets an important foundation for the higher natural nutrient capacity in black soil because the fine particles (such as clay) have a large specific surface area, which can absorb more nutrients.

Table 1. Soil mechanical composition characteristics in different locations (\%).

\begin{tabular}{ccccc}
\hline Location & Clay $(<\mathbf{4} \boldsymbol{\mu m})$ & Fine Silt $(\mathbf{4 - 1 6} \boldsymbol{\mu m})$ & Coarse Silt $(\mathbf{1 6 - 6 3} \boldsymbol{\mu m})$ & Sand $(>\mathbf{6 3} \boldsymbol{\mu m})$ \\
\hline Baiquan & $51.68 \pm 10.86^{\mathrm{a}}$ & $40.14 \pm 7.67^{\mathrm{a}}$ & $7.70 \pm 6.63^{\mathrm{d}}$ & $0.47 \pm 0.69^{\mathrm{c}}$ \\
Kedong & $46.33 \pm 16.73^{\mathrm{a}}$ & $35.81 \pm 8.87^{\mathrm{a}}$ & $16.56 \pm 10.14^{\mathrm{c}}$ & $1.29 \pm 1.03^{\mathrm{c}}$ \\
Keshan & $27.45 \pm 4.85^{\mathrm{b}}$ & $36.30 \pm 3.52^{\mathrm{a}}$ & $33.78 \pm 5.65^{\mathrm{a}}$ & $2.47 \pm 1.23^{\mathrm{c}}$ \\
Beian & $24.22 \pm 4.96^{\mathrm{b}}$ & $37.95 \pm 3.12^{\mathrm{a}}$ & $35.38 \pm 5.91^{\mathrm{a}}$ & $2.43 \pm 0.97^{\mathrm{c}}$ \\
Yian & $24.07 \pm 7.92^{\mathrm{b}}$ & $29.93 \pm 6.68^{\mathrm{b}}$ & $34.22 \pm 9.85^{\mathrm{a}}$ & $11.77 \pm 9.92^{\mathrm{b}}$ \\
Lindian & $30.56 \pm 7.78^{\mathrm{b}}$ & $30.41 \pm 5.98^{\mathrm{b}}$ & $27.95 \pm 8.77^{\mathrm{b}}$ & $11.08 \pm 7.73^{\mathrm{b}}$ \\
Fuyu & $28.62 \pm 14.66^{\mathrm{b}}$ & $23.14 \pm 10.88^{\mathrm{c}}$ & $17.23 \pm 7.40^{\mathrm{c}}$ & $31.00 \pm 24.84^{\mathrm{a}}$ \\
Mean & $32.51 \pm 14.07$ & $33.33 \pm 8.68^{\mathrm{a}}$ & $25.46 \pm 12.55$ & $8.70 \pm 14.24$ \\
\hline
\end{tabular}

Note: the numbers in each cell are mean \pm standard deviation; different letters represent significant differences $(p>0.05)$ with $\mathrm{a}$ is significantly greater than $\mathrm{b}$ and $\mathrm{c}, \mathrm{b}$ is significantly greater than $\mathrm{c}$.

There were significant differences in particle size mechanical compositions across the sampling regions (Table 1). The highest clay, silt and sand contents were found in BQ and KD (51.68\% and $46.33 \%), \mathrm{BA}$ and KS (73.34\% and 70.07\%), and FY (30.82\%), respectively $(p<0.05)$. The black soil mechanical composition distribution followed the following trend: soils in BQ and KD consisted mainly of fine particles (clay and fine silt), soils in KS and BA consisted mainly of silt, LD and YA had higher soil sand content, and FY had the highest sand content as well as the largest mean particle diameter. Compared with other counties, $\mathrm{BQ}$ and $\mathrm{KD}$ had the highest relative forest cover rates and lowest arable land cover rates. Forest land has a strong function of water and soil conservation, and low arable land cover rates are associated with low human disturbance; these are the reasons why $\mathrm{BQ}$ and $\mathrm{KD}$ have finer particles.

Soil particle size parameters can reveal the source of parent materials, source of deposit materials, transportation media, and kinetic energy conditions, along with recent environment changes and effects of human activities. The agricultural surface soil particle size parameters in the studied areas are shown in Table 2. The medium soil particle diameter (Md) ranged from 1.71 to $142.67 \mu \mathrm{m}$, with a mean diameter of $13.07 \mu \mathrm{m}$ and a coefficient of variation of $60 \%$, which represents medium variation, indicating that the soil was mainly made up of fine silt particles with relatively large overall variations. Standard deviation (i) ranged from 6.35 to 20.61, indicating variegated sortability from easily sorted to poorly sorted. Skewedness (Sk) ranged from -2.15 to 1.25 , with a mean of -0.18 . Kurtosis $(\mathrm{Kg})$ ranged from -1.33 and 2.91, between narrow-peaked normal distribution to polymodal wide peaks. The values of these parameters varied significantly across different sampling locations. This could be because soil particle size was affected by different subsets of environmental conditions at different locations, such as environments of soil formation, deposit transportation conditions, and human activities.

Comparing the soil particle size parameters across the sampling locations, we can deduce that $\mathrm{BQ}$ and $\mathrm{KD}$ had finer particles that loosely followed normal or lightly skewed normal distribution, indicating a single soil source and low transportation media kinetic energy. KS and BA had coarser soil particles and more skewed particle size distribution. LD, YA, and FY had coarsened and poorly sortable soil particles, indicating relatively complex source materials, especially in FY where the deposit transportation media showed significantly higher kinetic energy than all other locations. The coarser particles were more susceptible to impacts from the environment. 
Table 2. Characteristics of soil particle size parameters in different locations.

\begin{tabular}{ccccc}
\hline Location & $\begin{array}{c}\text { Medium Diameter } \\
\left(\boldsymbol{M}_{\boldsymbol{d}} / \boldsymbol{\mu \mathbf { m } )}\right.\end{array}$ & $\begin{array}{c}\text { Standard Deviation } \\
\left(\boldsymbol{\sigma}_{\boldsymbol{i}}\right)\end{array}$ & Skewedness $(\mathbf{S k})$ & Kurtosis $(\mathbf{K g})$ \\
\hline Baiquan & $3.63 \pm 1.13$ & $8.27 \pm 1.20$ & $0.23 \pm 0.40$ & $0.02 \pm 0.34$ \\
Kedong & $4.65 \pm 2.12$ & $9.72 \pm 1.25$ & $0.29 \pm 0.47$ & $-0.15 \pm 0.55$ \\
Keshan & $8.91 \pm 2.25$ & $10.57 \pm 0.61$ & $-0.45 \pm 0.34$ & $-0.52 \pm 0.25$ \\
Beian & $9.76 \pm 2.03$ & $10.27 \pm 0.51$ & $-0.58 \pm 0.31$ & $-0.30 \pm 0.29$ \\
Yian & $10.29 \pm 5.75$ & $12.42 \pm 1.68$ & $-0.01 \pm 0.64$ & $-0.59 \pm 0.37$ \\
Lindian & $13.95 \pm 7.84$ & $12.07 \pm 1.71$ & $-0.35 \pm 0.58$ & $-0.38 \pm 0.43$ \\
Fuyu & $39.90 \pm 49.98$ & $15.13 \pm 2.99$ & $-0.26 \pm 1.16$ & $0.08 \pm 1.11$ \\
Mean & $13.07 \pm 21.62$ & $11.26 \pm 2.55$ & $-0.18 \pm 0.67$ & $-0.28 \pm 0.58$ \\
\hline
\end{tabular}

\subsection{Soil Particle Size Frequency Distribution Curves}

Soil particle size mechanical compositions and other parameters all indicated that the soils in the studied areas originated from multiple sources and were beginning to display particle coarsening. The particle size frequency distribution curve can faithfully reflect the sources of the deposits, the relationship between the deposits, the transportation media, and changes in transportation conditions. As a result, isolating and calculating the contribution of soil-sensitive components from particle size frequency curves, using the lognormal distribution function, can reveal the sources and shaping forces of the soil, and help quantify the impact from environmental changes and human activities. When soil particles develop under stable soil-forming conditions, i.e., without or with very little external disturbance, the particle size frequency distribution curve usually follows a single-peaked log-normal distribution. When the soil is heavily disturbed by environmental changes or human activities, the particle size frequency distribution curve displays a multi-component and polymodal distribution [18].

Four particle size-sensitive components (from fine to coarse) were identified from the particle size frequency curves of all 116 black soil samples. Component 1 (C1) was made up of clay particles $(<2 \mu \mathrm{m})$, with the particle diameter frequency peaking at $0.7 \mu \mathrm{m}$; component 2 (C2) was mainly made up of fine silt particles $(2-15 \mu \mathrm{m})$, with the particle diameter frequency peaking at 5-8 $\mu \mathrm{m}$; component 3 (C3) was made up of coarse silt particles $(15-65 \mu \mathrm{m})$, with the particle diameter frequency peaking at $40-50 \mu \mathrm{m}$; and component 4 (C4) was made up of sand particles $(>65 \mu \mathrm{m})$, with the particle diameter frequency peaking at $500 \mu \mathrm{m}$ (Figure 2a). Log-normal distribution function fitting of all particle size frequency curves yielded the percentages of each of the components in each soil sample, reflecting the contribution rate of different soil formation forces. The contribution rates of $\mathrm{C} 1$ to $\mathrm{C} 4$ ranged from $1-13 \%, 16-99 \%, 0-70 \%$, and $0-82 \%$, respectively, with coefficient of variations of $41 \%, 33 \%, 75 \%$, and $296 \%$, respectively.

ANOVA analysis of the contribution rates of the four components across seven locations is shown in Table 3 . The contribution rate of $\mathrm{C} 1$ did not differ significantly among locations, with an average weight percentage of $<5 \%$ at each location. Significant differences of contribution rates were found in $\mathrm{C} 2, \mathrm{C} 3$, and $\mathrm{C} 4$ across locations $(p<0.05)$. C2 counted towards the highest weight percentage in $\mathrm{BQ}$ and $\mathrm{KD}$ and the lowest in LD and FY. C3 contributed higher in KS, BA, YA, and LD than in other locations. C4 mainly existed in YA, LD, and FY, and was significantly enriched in FY. The results from the present study indicate that the overall contribution rate of $\mathrm{C} 1$ was low and in a consistent part of soils across different locations. C2 showed the lowest coefficient of variation and highest contribution rate across all locations, suggesting that it was the most stable component as well as the main body of the soils in the studied regions. C3 and C4 contents were highly variable across locations, indicating susceptibility to environmental impacts. 

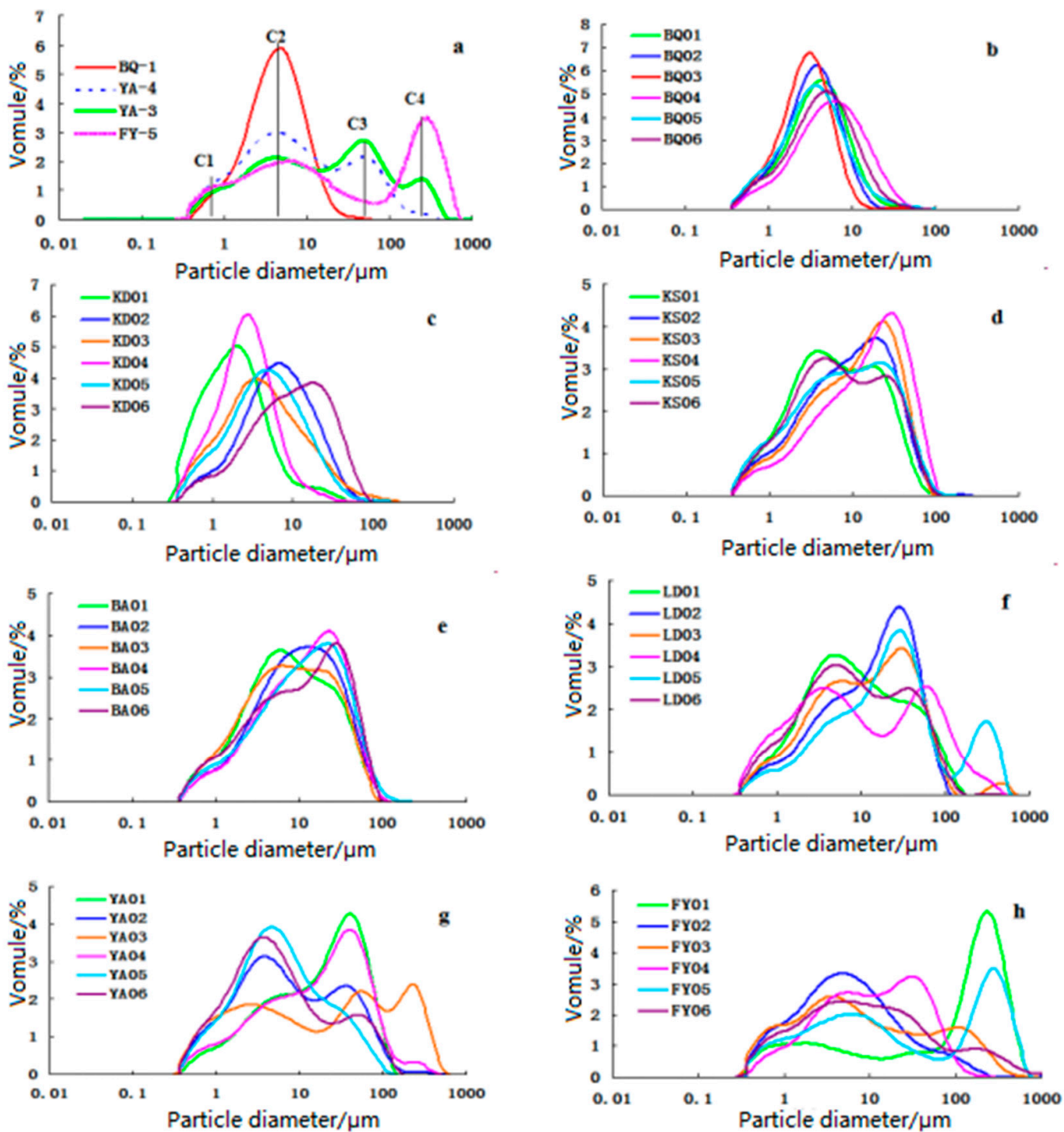

Figure 2. Typical particle size frequency curves and particle size frequency curves in different counties. (a) Typical particle size frequency curves; $(\mathbf{b}-\mathbf{h})$ particle size frequency curves in Baiquan County, Kedong County, Keshan County, Beian City, Lindian County, Yian County, and Fuyu County.

Table 3. Contribution rates of soil particle size-sensitive components in different locations (\%).

\begin{tabular}{cccccccc}
\hline Components & Baiquan & Kedong & Keshan & Beian & Yian & Lindian & Fuyu \\
\hline $\mathrm{C} 1$ & 5.22 & 4.43 & 4.93 & 4.71 & 4.08 & 4.12 & 5.22 \\
$\mathrm{C} 2$ & $92.12^{\mathrm{a}}$ & $86.55^{\mathrm{ab}}$ & $50.86^{\mathrm{d}}$ & $63.00^{\mathrm{c}}$ & $64.19^{\mathrm{c}}$ & $49.91^{\mathrm{d}}$ & $49.63^{\mathrm{d}}$ \\
$\mathrm{C} 3$ & $2.67^{\mathrm{d}}$ & $9.02^{\mathrm{cd}}$ & $44.21^{\mathrm{a}}$ & $32.29^{\mathrm{b}}$ & $30.32^{\mathrm{b}}$ & $42.69^{\mathrm{a}}$ & $12.20^{\mathrm{c}}$ \\
$\mathrm{C} 4$ & $0^{\mathrm{b}}$ & $0^{\mathrm{b}}$ & $0^{\mathrm{b}}$ & $0^{\mathrm{b}}$ & $1.46^{\mathrm{b}}$ & $3.28^{\mathrm{b}}$ & $32.95^{\mathrm{a}}$ \\
\hline
\end{tabular}

Note: different letters in each row represent significant differences $(p>0.05)$ with the order of significance from most to least is $\mathrm{a}>\mathrm{b}>\mathrm{c}>\mathrm{d}$.

Figure $2 \mathrm{~b}-\mathrm{h}$ are the soil particle size frequency curves of samples from seven locations. All frequency curves displayed polymodal characteristics with relatively clear locational differences. Particle size frequency curves of $B Q$ and KD displayed a near-symmetrical lightly right-skewed bi-modal distribution (Figure $2 \mathrm{~b}, \mathrm{c}$ ) with good soil sortability (better sortability in $\mathrm{BQ}$ than in $\mathrm{KD}$ ). The main peaks in the curves represent the high-content $\mathrm{C} 2$, and the secondary peaks represent the lower-content $\mathrm{C} 1$. Frequency curves of KS and BA showed a tri-modal distribution (Figure $2 \mathrm{~d}$,e), with the two main peaks representing $\mathrm{C} 2$ and C3 (both high-content), and the secondary peak representing low-content $\mathrm{C} 1$. Frequency 
curves in LD, YA, and FY showed quad-modal distribution (Figure $2 \mathrm{f}-\mathrm{h}$ ) with poor soil sortability. In LD and YA frequency curves, the main peaks represented $\mathrm{C} 2$ and $\mathrm{C} 3$ and the secondary peaks, $\mathrm{C} 4$ and $\mathrm{C} 1$. In the frequency curves of FY, the main peak represented C4, and the secondary peaks were $\mathrm{C} 2, \mathrm{C} 3$, and $\mathrm{C} 1$ components.

\subsection{Spatial Distribution of Contribution Rates of Soil Particle Size-Sensitive Components}

In order to intuitively understand the topsoil spatial distribution pattern in the studied area, the Kriging method under Geostatistics tools in ArcGIS 10.2 was used to perform optimized interpolation and visualization of the spatial distribution of each of the soil particle size-sensitive components (Figure 3). In Figure 3a, the contribution rate of $\mathrm{C} 1$ had the smallest variation within the studied area, showing no obvious spatial distribution patterns. Figure $3 \mathrm{~b}$ indicates that the $\mathrm{C} 2$ component had the highest contribution rate in $\mathrm{KD}$ and $\mathrm{BQ}$, and its contribution rate decreased from the center towards the eastern and western sides. The lowest $\mathrm{C} 2$ contribution rate appeared in the southwest corners of FY and LD. The $\mathrm{C} 3$ component constituted of coarse silt particles with the contribution rate ranked as $\mathrm{BQ}<\mathrm{KD}<\mathrm{FY}<\mathrm{YA}<\mathrm{BA}<\mathrm{LD}<\mathrm{KS}$ (Figure 3c). C4 was only found across the whole of FY and parts of LD and YA. The C4 contribution rate was highest in FY, as high as $32.95 \%$ (Figure 3d).

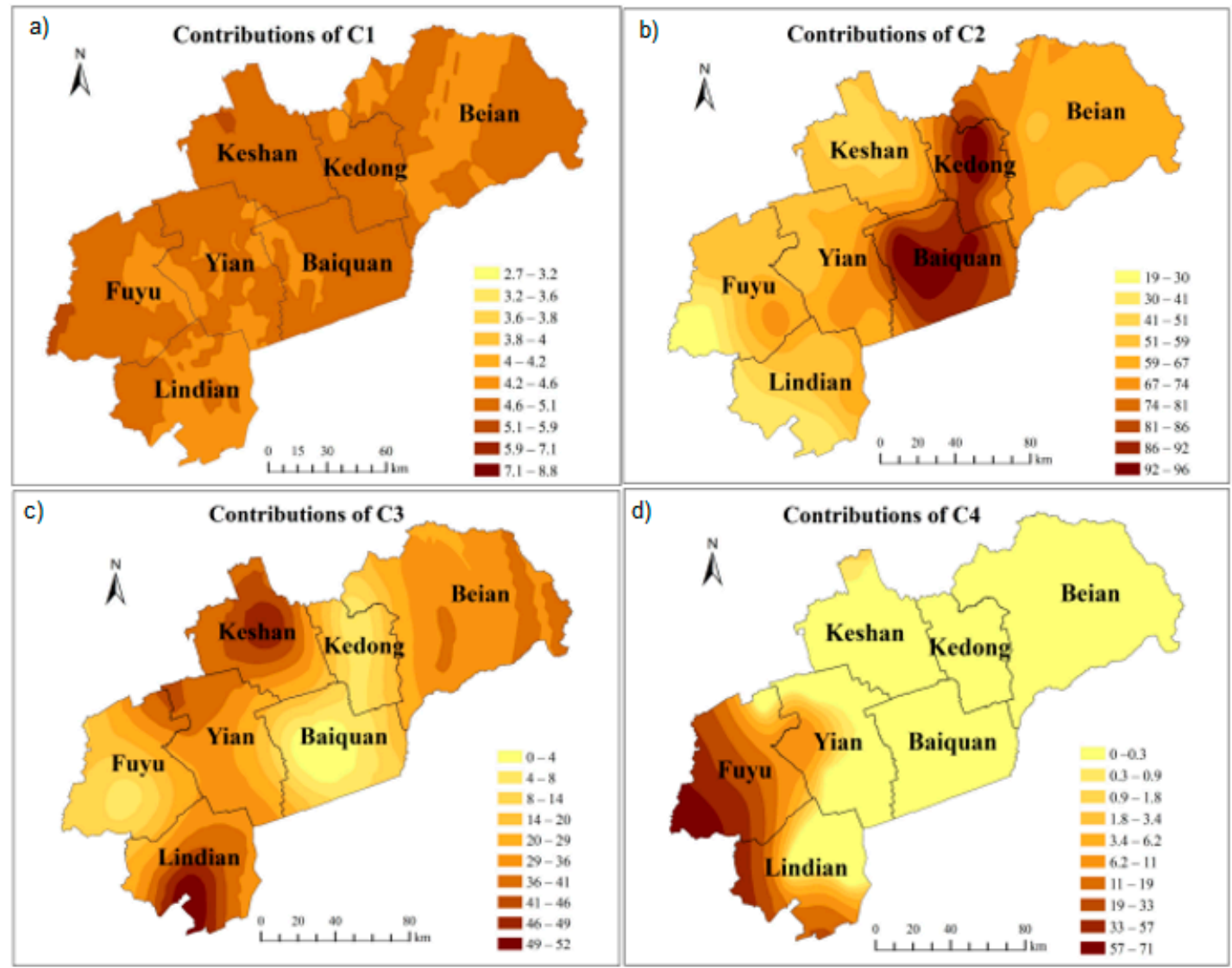

Figure 3. Spatial distributions of contribution rates of soil particle size-sensitive components. (a) C1 component; (b) C2 component; (c) C3 component; and (d) C4 component.

\section{Discussion}

\subsection{Environmental Implications of Soil Particle Size-Sensitive Components}

The multi-component feature of the soil particle size frequency curve is the combined manifestation of the transportation and deposit effects of topology, hydrology, temperature, other external environmental forces, and human activities acting upon the foundation of parent materials. Among these forces, soil particles primarily retain characteristics of their 
parent materials. As a result, the soil component developed from local parental materials usually takes up the largest and most stable proportion in a particle size frequency diagram. In the current research, environmentally sensitive components, C1-C4, from black soil particle size frequency curves were extracted, each of which took up an average of $4.68 \%$, $64.54 \%, 35.26 \%$, and $28.56 \%$ of total dry weight, respectively. Among the four components, $\mathrm{C} 2$ had a significantly higher contribution rate to total weight when compared to the other components and the lowest coefficient of variation across samples and locations. We can, therefore, infer that this sensitive component, $\mathrm{C} 2$, within which the maximum particle diameter frequency was found within the range of $2-15 \mu \mathrm{m}$, represents the fine silt particles developed from local parent materials. These results were in accord with the observation that fine silt was the dominant soil mechanical composition of black soil. The spatial difference between its contribution rates across locations mostly resulted from the uneven spatial distribution of other components.

The particle size frequency curve can reveal the relationship between soil particles, environmental media, and transportation modes, as well as transportation conditions and intensity of transportation, making particle size frequency curves a useful tool in studying wind erosion, land desertification, and sandstorms [20,29,30]. Particle diameter determines soil particle release, transportation, and deposition during soil wind erosion. Surface soil particle diameter features can point out signatures and intensity of wind erosion events [31]. Northeastern China is located in a semi-arid, semi-humid monsoon climate zone, where monsoon-affected wind erosion, transportation, and deposition of soil particles commonly exist. Particles of different diameters are transported through different media and across different distances in the environment. Studies have shown that particles smaller than $70 \mu \mathrm{m}$ in diameter can be transported in the air along atmospheric movements [20]. Among the airborne particles, clay particles smaller than $20 \mu \mathrm{m}$ can be transported across long distances, up to thousands of kilometers, in suspension form. Silt particles 20-70 $\mu \mathrm{m}$ can travel by saltation near the ground surface within limited distance ranges. Soil particles larger than $500 \mu \mathrm{m}$ mostly move very slowly close to the land surface. Particles that travel in air suspension or through saltation tend to land on soil surfaces when wind speed reduces or when land surface traction increases [20,32].

In this study, the sensitive component $\mathrm{C} 1$ consisted of clay particles with a maximum diameter frequency centered around $0.7 \mu \mathrm{m}$, counted toward less than $5 \%$ of total soil dry weight, and did not have a significantly differentiated concentration across locations. These features suggest that $\mathrm{C} 1$ originated from commonly existing external environmental factors. The particle size distribution of $\mathrm{C} 1$ also resembles the commonly accepted size of atmospheric dust [31,33]. Atmospheric dusts are the clay particles that are suspended in air and travel across long distances. Therefore, $\mathrm{C} 1$ likely resulted from stable weak forces from the atmosphere, pointing towards the atmospheric background dust controlled by the westerly circulation [31]. Component C3, larger in particle diameter (maximum diameter frequency $40-50 \mu \mathrm{m}$ ), reveals the outcome of short-distance saltation. The features of C3 corresponded with known signatures of soil wind erosion, as atmospheric forces can transport and deposit clay and silt particles, and coarser particle components are the result of short-distance low-altitude transportation [11,13,14,31,34]. Besides, studies that used river and lake sediment particle size frequency curves to deduce regional wind erosion intensity also treated particles with diameters between $10 \mu \mathrm{m}$ and $70 \mu \mathrm{m}$ as an indicator of wind intensity within the watershed [20]. Therefore, the particle size-sensitive component C3 is diagnostic for wind erosion effects in the northeastern black soil region. It has been reported that the soil erosion area in the black soil region in northeast China is $74,326.2 \mathrm{~km}^{2}$, while the wind erosion area is about $22,448.2 \mathrm{~km}^{2}$, accounting for $30.2 \%$ of the total erosion area [35]. Spring and autumn seasons in the studied areas are characterized by heavy wind and high evaporation rate because the surface soil was dry and loose, resulting in low surface soil water content. Furthermore, because the black soil region is located in the seasonal frozen soil area, the freeze-thaw cycle could decrease bulk density, loosen structure, and weaken corrosion-resistance of soil, which creates favorable conditions 
for wind erosion. If exposed land areas, such as agricultural lands, are not protected by windbreak forests, coarse silt particles are extremely susceptible to short-distance lowaltitude wind transportation, resulting in the increased contribution rate of wind-erosion component (C3).

The sensitive component $C 4$ consisted of all particles larger than $65 \mu \mathrm{m}$ in diameter. The maximum particle diameter frequency was over $500 \mu \mathrm{m}$, exceeding the particle size limitation for wind-powered short-distance transportation. This soil component mainly travels within very short distances close to the ground surface and is commonly associated with frequent human agricultural activities. One of most serious problems in northeast China is overuse and low maintenance and weak awareness of black soil protection, which have caused the deterioration of physical properties, decreased water stable soil aggregate structure, and declined cohesion among the soil particles. Hence, the C4 component within the studied area showed very high variation, with a strongly differentiated presence across spatial coordinates, indicating soil coarsening and sandification due to the reduced erosion-resistance as a result of the loss of clay and silt particles during strong mechanical disturbance and irrigation.

The interpretations and implications of the black soil particle size frequency distribution diagram in this study are in agreement with the results of the particle origin analysis in the soil particle size study conducted by Jin et al. [36], looking at surface soil in the Yili River Valley. From the above results, we can conclude that the agricultural topsoil in the studied area had multiple origins. We deduced that the black soil in this area is a mixture of locally developed soil, successions of local parent materials (C2), clay dust transported through atmospheric movements (C1), coarse silt transported over short distances (C3), and sandy particles enriched from human disturbance (C4).

\subsection{Spatial Differentiation of Contribution Rates of Soil Particle Size-Sensitive Components Distributions}

Component $\mathrm{C} 1$ belongs to fine clay particles which originated from a constantly present environmental factor-dust transported across long distances carried by a highaltitude air current-making up the background values for atmospheric dust. C2 was derived from local parent materials, which had low spatial variation within and across locations. The spatial distribution pattern of $\mathrm{C} 2$ was mostly determined by the regional differentiation in the contribution rates of $\mathrm{C} 3$ and $\mathrm{C} 4$. Figure $3 c, \mathrm{~d}$ demonstrate the spatial distribution of the contribution rates of coarse silt particles associated with the wind erosion process (C3) and sand particles associated with human disturbance (C4), respectively. C3 was commonly found across the entire studied area, indicating the prevalence of wind erosion and transportation in the area. $\mathrm{BQ}$ and $\mathrm{KD}$ experienced the least wind erosion, with the $\mathrm{C} 3$ contribution rate below $10 \%$. KS and LD experience the most severe wind erosion, with the C3 contribution rate above $40 \%$. This suggests the highest degree of human disturbance in agricultural topsoil was in Fuyu. The contribution rate of $\mathrm{C} 4$ in other counties was lower than $5 \%$, indicating a low level of human disturbance.

The combined contribution rate of $\mathrm{C} 3$ and $\mathrm{C} 4$ could indicate the total soil coarsening caused by wind erosion along with human activities. Soil particle size coarsening in the sampled locations ranked as BQ $(2.67 \%)<\mathrm{KD}(9.02 \%)<\mathrm{YA}(31.78 \%)<\mathrm{BA}(32.29 \%)<\mathrm{KS}$ $(44.21 \%)<\mathrm{FY}(45.16 \%)<\mathrm{LD}(45.97 \%)$. The lightest degree of soil coarsening was found in $\mathrm{BQ}$ and $\mathrm{KD}$, with a combined C3 and C4 contribution rate below $10 \%$, followed by YA and $\mathrm{BA}$, where coarsened particles contributed to around $30 \%$ of the soil total weight. KS, LD, and FY suffered from the most serious soil coarsening, with more than $40 \%$, up to $44.21 \%$, of total surface soil affected by erosion and disturbance. After dissecting the total soil coarsening percentage into wind erosion effects and human activity effects, it was shown that $12.20 \%$ of soil coarsening in FY resulted from wind erosion. The proportions of arable land of the seven regions in 2014 were counted to evaluate the degree of anthropogenic disturbance to topsoil, which ranked as BQ $(69.9 \%)<\mathrm{KD}(78.7 \%)<\mathrm{YA}(88.5 \%)<\mathrm{BA}$ $(92.1 \%)<$ KS $(94.0 \%)<\operatorname{LD}(95.7 \%)<$ FY $(96.5 \%)$ in Figure 4 . The highest proportion of arable land in FY indicated that the majority of soil coarsening resulted from human 
activities by agricultural cultivation. Therefore, we can conclude that soil degradation in FY mainly resulted from human disturbance. Active management and regulation of human disturbance of surface soil should be implemented to protect topsoil and control soil degradation. In windy weather, wind erosion easily occurred in the surface soil of arable land with more human disturbance. Wind erosion contributed more to soil degradation than human activities in all other locations. As a result, soil protection acts in these areas should focus on defense against wind erosion. Planting windbreak forests should be encouraged in these areas. In order to more accurately study the specific characteristics of wind erosion, such as the erosion intensity, effect factors of wind erosion, and the scope of wind erosion. Control simulation tests are needed in the future, and more soil physical and chemical indexing (soil moisture content, soil organic carbon, and $\mathrm{pH}$ value) is necessary.

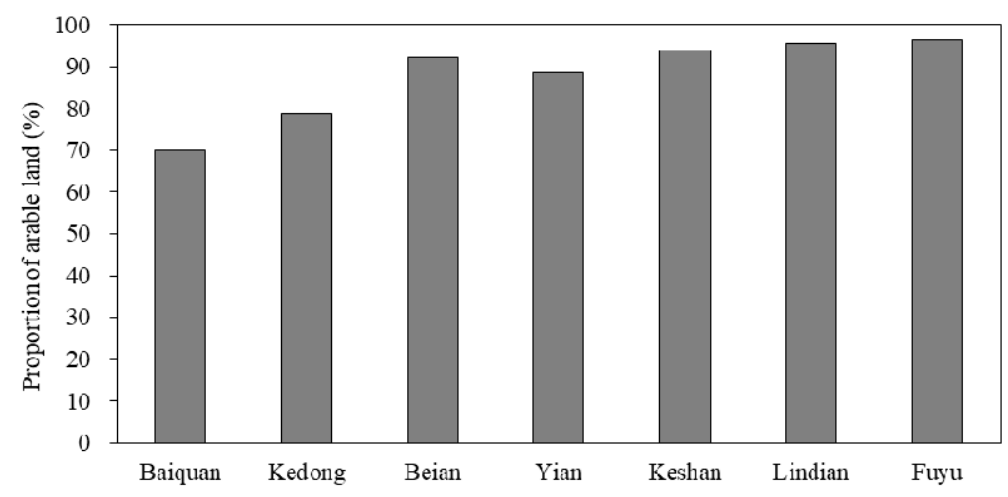

Figure 4. Proportion of arable land of different locations (\%).

\section{Conclusions}

The qualitative and quantitative degradation of Chinese northeast black soil is of great significance to food security and sustainable development. Particle size components, particle size environmentally sensitive components, and their indicating significances were evaluated to investigate the spatial characteristics of black soil degradation. In general, the mechanical composition of surface soil in the studied area was found to be silt (17.7-80.3\%) $>$ clay $(7.8-79.3 \%)>$ sand $(0-73.7 \%)$. A relatively high content of clay particles was found in surface black soil samples, which was significantly higher than that of Quaternary red earth, purplish soil, and loess. This feature is the main reason for the higher natural nutrient capacity in black soil.

Log-normal distribution function fitting was applied to extract sensitive components that affected the soil. Four environmentally sensitive components of $\mathrm{C} 1(<2 \mu \mathrm{m}), \mathrm{C} 2$ $(2-15 \mu \mathrm{m}), \mathrm{C} 3(15-65 \mu \mathrm{m})$, and C4 (>65 $\mu \mathrm{m})$ were identified, and their contribution rates were calculated to further reveal the impact of different factors on the black soil. $\mathrm{C} 1$ had the lowest contribution rate and did not differ across locations, representing airborne dust transported from long distances away. It was caused by clay particles smaller than $20 \mu \mathrm{m}$ which can be transported across long distances, up to thousands of kilometers, in suspension form. C2 had the highest contribution rate and lowest variability, representing locally developed soil from parent materials. The significantly higher contribution rate of $\mathrm{C} 2$ in Baiquan and Kedong than any other locations was mostly determined by regional differentiation in the contribution rates of C3 and C4. C3 had a larger particle diameter, less than 65 $\mu \mathrm{m}$, which can travel by short-distance saltation due to the monsoon-affected wind erosion. The soil coarsening observed in the studied area mainly resulted from a wind erosion effect, with minor and location-specific contributions from human activities. C4 consisted of all particles larger than $65 \mu \mathrm{m}$, representing effects of strong human disturbance.

Among the sampled locations, soil conditions were the best in Baiquan and Kedong, with soil coarsening occurring in less than $10 \%$ of total soil. Keshan, Lindian, and Fuyu were experiencing the most severe soil coarsening, with more than $40 \%$ of total soil impacted by erosion and disturbance processes. The contents of $\mathrm{C} 3$ and $\mathrm{C} 4$ were highly variable within 
and across locations and were especially higher in Fuyu. The highest proportion of arable land in Fuyu caused the majority of soil coarsening and resulted from human activities by agricultural cultivation. Active management and regulation of human disturbance of surface soil should be implemented to protect topsoil and control soil degradation. Wind erosion contributed more to soil degradation than human activities in all other locations. As a result, soil protection acts in these areas should focus on defense against wind erosion. Planting windbreak forests should be encouraged in these areas.

Author Contributions: Conceptualization, L.S. and S.Z.; methodology, Y.Z.; software, Y.Z.; validation, L.S., B.Y., and Q.C.; investigation, Q.C.; data analysis, Y.Z. and Q.C.; Writing-Original draft preparation, Y.Z. and B.Y.; Writing-Review and editing, L.S.; funding acquisition, L.S., Y.Z., and S.Z. All authors have read and agreed to the published version of the manuscript.

Funding: This research was funded by the National Key Research and Development Project of China, grant number 2016YFC0500404-6, the National Natural Science Foundation of China, grant numbers 41401589 and 41971151, the Natural Science Foundation of Heilongjiang Province, grant number YQ2019D005, and the Graduate Innovative Programs Foundation of Harbin Normal University, grant number HSDSSCX2015-12.

Institutional Review Board Statement: Not applicable.

Informed Consent Statement: Not applicable.

Data Availability Statement: The data presented in this study are available on request from the corresponding authors.

Acknowledgments: We would like to thank the editors and the anonymous reviewers for their help and guidance.

Conflicts of Interest: The authors declare no conflict of interest.

\section{References}

1. Miranda, J.; Montero, E.; Alves, M.; González, A.P.; Vázquez, E.V. Multifractal characterization of saprolite particle-size distributions after topsoil removal. Geoderma 2006, 134, 373-385. [CrossRef]

2. Zhang, X.; Zhang, W.W.; Wang, L.X.; Liu, Y.X.; Liu, Y.; Feng, Q. Relationship between soil water content and soil particle size on typical slopes of the Loess Plateau during a drought year. Sci. Total Environ. 2019, 648, 943-954. [CrossRef] [PubMed]

3. Visher, G.S. Grain Size Distributions and Depositional Processes. J. Sediment. Res. 1969, 39, 1074-1106.

4. Rabot, E.; Wiesmeier, M.; Schlüter, S.; Vogel, H.-J. Soil structure as an indicator of soil functions: A review. Geoderma 2018, 314, 122-137. [CrossRef]

5. Wang, Z.; Zhang, B.; Zhang, S.; Li, X.; Liu, D.; Song, K.; Li, J.; Li, F.; Duan, H. Changes of Land Use and of Ecosystem Service Values in Sanjiang Plain, Northeast China. Environ. Monit. Assess. 2006, 112, 69-91. [CrossRef] [PubMed]

6. Cosby, B.J.; Hornberger, G.M.; Clapp, R.B.; Ginn, T.R. A statistical exploration of the relationships of soil moisture character-istics to the physical properties of soils. Water Resour. Res. 1984, 20, 682-690. [CrossRef]

7. Singer, A.; Zobeek, T.; Poberezsky, L.; Argaman, E. The PM10 and PM2.5 dust generation potential of soils/sediment in the Souhtern Aral Sea Basin, Ubzekistan. J. Arid Environ. 2003, 54, 705-728. [CrossRef]

8. Orlovsky, L.; Orlovsky, N.; Durdyev, A. Duststorms in Turkmenistan. J. Arid Environ. 2005, 60, 87-97. [CrossRef]

9. Iost, S.; Landgraf, D.; Makeschin, F. Chemical soil properties of reclaimed marsh soil from Zhejiang Province P.R. China. Geoderma 2007, 142, 245-250. [CrossRef]

10. Xiao, J.; Fan, J.; Zhai, D.; Wen, R.; Qin, X. Testing the model for linking grain-size component to lake level status of modern clastic lakes. Quat. Int. 2015, 355, 34-43. [CrossRef]

11. Shen, J.; Wang, Y.; Yang, X.; Zhang, E.; Yang, B.; Ji, J. Paleosandstorm characteristics and lake evolution history deduced from investigation on lacustrine sediments-The case of Hongjiannao Lake, Shaanxi Province. Chin. Sci. Bull. 2005, 50, $2355-2361$.

12. Menafoglio, A.; Guadagnini, A.; Secchi, P. Stochastic simulation of soil particle-size curves in heterogeneous aquifer systems through a Bayes space approach. Water Resour. Res. 2016, 52, 5708-5726. [CrossRef]

13. Pye, K. Aeolian Dust and Dust Deposits; Academic Press: London, UK, 1987.

14. Sun, D.; Bloemendal, J.; Rea, D.; Vandenberghe, J.; Jiang, F.; An, Z.; Su, R. Grain-size distribution function of polymodal sediments in hydraulic and aeolian environments, and numerical partitioning of the sedimentary components. Sediment. Geol. 2002, 152, 263-277. [CrossRef]

15. Boulay, S.; Colin, C.; Trentesaux, A.; Pluquet, F.; Bertaux, J.; Blamart, T.; Buehring, C.; Wang, P. Mineralogy and Sedimentology of Pleistocene Sediment in the South China Sea (ODP Site 1144). Proc. Ocean Drill. Program 2003, 184, 1-21. 
16. Frison, G.C.; Wimer, A.E.; Scoggin, W.E.; Walker, D.N.; Miller, J.C. Multi-component Paleoindian surface sites in the Great Divide Basin of Wyoming. Plains Anthropol. 2014, 60, 172-192. [CrossRef]

17. Qi, F.; Zhang, R.; Liu, X.; Niu, Y.; Zhang, H.; Li, H.; Li, J.; Wang, B.; Zhang, G. Soil particle size distribution characteristics of different land-use types in the Funiu mountainous region. Soil Tillage Res. 2018, 184, 45-51. [CrossRef]

18. Collins, A.L.; Walling, D.E.; Leeks, G.J.L. Fingerprinting the origin of fluvial suspended sediment in larger river basins: Combining assessment of spatial provenance and source type. Geogr. Ann. Ser. A Phys. Geogr. 1997, 79, 239-254. [CrossRef]

19. Chang, X.; Sun, L.; Yu, X.; Liu, Z.; Jia, G.; Wang, Y.; Zhu, X. Windbreak efficiency in controlling wind erosion and particulate matter concentrations from farmlands. Agric. Ecosyst. Environ. 2021, 308, 107269. [CrossRef]

20. Zhang, Z.C.; Dong, Z.B. The effect of wind erosion on the surface particle size. J. Arid Land Resour. Environ. 2012, 26, 86-89.

21. Yan, Y.C.; Tang, H.P.; Zhang, X.S.; Wang, X.; Wang, H.X. A probe into grassland wind erosion based on the analysis of soil particle size. J. Des. Res. 2010, 30, 1263-1268.

22. Duczek, S.; Gravenkamp, H. Mass lumping techniques in the spectral element method: On the equivalence of the row-sum, nodal quadrature, and diagonal scaling methods. Comput. Methods Appl. Mech. Eng. 2019, 353, 516-569. [CrossRef]

23. Wang, X.; Zhang, S.; Pan, H.; Zheng, Z.; Huang, Y.; Zhu, R. Effect of soil particle size on soil-subsoiler interactions using the discrete element method simulations. Biosyst. Eng. 2019, 182, 138-150. [CrossRef]

24. Ma, Y.; Minasny, B.; Welivitiya, W.D.P.; Malone, B.P.; Willgoose, G.R.; McBratney, A.B. The feasibility of predicting the spatial pattern of soil particle-size distribution using a pedogenesis model. Geoderma 2019, 341, 195-205. [CrossRef]

25. Liu, Z.; Zhang, Y.; Liu, B.; Zeng, L.; Xu, D.; He, F.; Kong, L.; Zhou, Q.; Wu, Z. Adsorption performance of modified bentonite granular (MBG) on sediment phosphorus in all fractions in the West Lake, Hangzhou, China. Ecol. Eng. 2017, 106, 124-131. [CrossRef]

26. Stille, H.; Palmström, A. Practical use of the concept of geotechnical categories in rock engineering. Tunn. Undergr. Space Technol. 2018, 79, 1-11. [CrossRef]

27. He, D.; Cui, J.; Gao, M.; Wang, W.; Zhou, J.; Yang, J.; Wang, J.; Li, Y.; Jiang, C.; Peng, Y. Effects of soil amendments applied on cadmium availability, soil enzyme activity, and plant uptake in contaminated purple soil. Sci. Total Environ. 2019, 654, 1364-1371. [CrossRef] [PubMed]

28. Zhu, Y.J.; Jia, X.X.; Qiao, J.B.; Shao, M.A. What is the mass of loess in the Loess Plateau of China? Sci. Bull. 2019, 64, 534-539. [CrossRef]

29. Di, X.; Xiao, B.; Dong, H.; Wang, S. Implication of different humic acid fractions in soils under karst rocky desertification. Catena 2019, 174, 308-315. [CrossRef]

30. Yuan, T.; Chen, S.; Huang, J.; Zhang, X.; Luo, Y.; Ma, X.; Zhang, G. Sensitivity of simulating a dust storm over Central Asia to different dust schemes using the WRF-Chem model. Atmos. Environ. 2019, 207, 16-29. [CrossRef]

31. Al Badi, H.; Boland, J.; Bruce, D.; Wedding, B. Estimating effective dust particle size from satellite observations. Remote. Sens. Appl. Soc. Environ. 2018, 11, 186-197.

32. Bian, B.; Zhu, W. Particle size distribution and pollutants in road-deposited sediments in different areas of Zhenjiang, China. Environ. Geochem. Health 2008, 31, 511-520. [CrossRef] [PubMed]

33. Hwang, D.-C.; Shin, D.-H.; Kim, S.-C.; Kim, E.-S. Depth extraction of three-dimensional objects in space by the computational integral imaging reconstruction technique. Appl. Opt. 2008, 47, 128-135. [CrossRef] [PubMed]

34. Tsoar, H.; Pye, K. Dust transport and the question of desert loess formation. Sedimentology 1987, 34, 139-153. [CrossRef]

35. Liu, T.J.; Shan, D.; Guo, J.Y.; Gao, T.M.; Zhao, X.B. Analysis on status and development trend of wind erosion in black earth region of Northeast China. Agric. Sci. Technol. 2011, 12, 1925-1928.

36. Jin, J.H.; Li, Z.Z.; Ling, Z.Y.; Ma, P.; Wu, M.R.; Qi, S.J. Spatial distribution of surface soil particles in a newly reclaimed area in Ili Valley. Bull. Soil Water Conserv. 2010, 30,7-16. 